\title{
Electrochemical Characterization of Al 1100 Alloy in Different Concentration of Ammonium Chloride Solution at Laboratory Temperature
}

Pruthviraj RD* and Vishwa Prakash

Department of Chemistry, Raja Rajeswari College of Engineering, Bangalore, Karnataka, India

"Corresponding author: Pruthviraj RD, Department of Chemistry, Raja Rajeswari College of Engineering, Bangalore, Karnataka, India, Tel: 08028437124; E-mail: pruthvirajrd@gmail.com

Received date: Sep 14, 2017; Accepted date: Sep 19, 2017; Published date: Sep 26, 2017

Copyright: ( 2017 Pruthviraj RD, et al. This is an open-access article distributed under the terms of the Creative Commons Attribution License, which permits unrestricted use, distribution, and reproduction in any medium, provided the original author and source are credited.

\begin{abstract}
In this study of $\mathrm{Al} 1100$ alloy is selected, the corrosion test was conducted at room temp using Electrochemical studies. The corrodent medium used for the test was $1 \mathrm{M}, 75 \mathrm{M}, 0.5 \mathrm{M}$ and $0.25 \mathrm{M}$ Ammonium chloride solution. The specimen was washed with distilled water fallowed by acetone and allowed to dry thoroughly the corrodent specimen was cleaned with brush for remove adhering corrosion product washed with water and acetone, then dried. The corrosion rates are calculated using $\mathrm{CH}$-Instrument. In each case the corrosion rate in ammonium chloride solution decreases and the corrosion becomes decrease in exposure time for Al alloy due to the aluminium in many induced passivation due to the formation of metal chloride layer.
\end{abstract}

Keywords: $\mathrm{Al} 1100$ alloy; $\mathrm{NH}_{4} \mathrm{Cl}$; Weight loss; Electrochemical studies; Impedance; XRD; SEM

\section{Introduction}

Designers get many advanced benefits in designing the components for automobile and aircraft industry through metal matrix composites. In most composites reinforcement is added to the matrix of the bulk material to increase strength and stiffness of the matrix [1-3]. A reduction in material density coupled with an increase in stiffness yield strength can be translated to reduction of structural weight.

\section{Experimental Procedure}

Although series of Al alloy like 2xx, 3xx, 6xx are available $\mathrm{Al} 1100$ alloy as matrix has been identified since it has potential applications in aircraft and space industries because of lower weight to strength ratio high wear resistance, $\mathrm{Al} 100$ is a wrought alloy was chosen at the matrix material as shown in Table 1.

\begin{tabular}{|l|l|l|l|l|l|l|l|l|l|l|l|}
\hline Alloy & $\mathbf{Z n}$ & $\mathbf{M g}$ & $\mathbf{C u}$ & $\mathbf{C r}$ & $\mathbf{F e}$ & $\mathbf{T i}$ & $\mathbf{S i}$ & $\mathbf{M n}$ & $\mathbf{N i}$ & $\mathbf{S n}$ & $\mathbf{A l}$ \\
\hline Percent & 5.339 & 2.156 & 1.252 & 0.208 & 0.133 & 0.24 & 0.018 & 0.011 & 0.011 & 0.028 & Remain \\
\hline
\end{tabular}

Table 1: The composition of $\mathrm{Al} 1100$.

\section{Specimen preparation}

The cylindrical mould material was cut into $20 \times 20 \mathrm{~mm}$ pieces using abrasive cutting wheel. Polished according to the metallographic techniques washed with acetone then with distilled water and dried [4-6]. The samples were weighed up to the fourth decimal place using electronic balance and also the specimen dimensions were noted down using vernier guaze.

\section{Corrosion test}

The corrosion test behavior of aluminium 1100 alloy used for the studied of the immersion test. The static immersion corrosion method was adopted to measure of the corrosion loss. The corrosion test behavior of $\mathrm{Al} 1100$ alloy was studied by the immersion test $[7,8]$. The static immersion corrosion method was adopted to measure the corrosion loss. $1 \mathrm{M} \mathrm{NH}_{4} \mathrm{Cl}$ was used for this purposed. $200 \mathrm{ml}$ of the prepared solution was taken in the beaker sample were suspended in the corrosive medium for different time of intervals up to 96 hours in the steps of $24 \mathrm{hrs}$. To minimize the contamination of the aqueous solution and loss due to evaporation, the beakers were covered with paraffin papers during the entire test period. After the specified time the samples were cleaned mechanically by using a brush in order to remove heavy corrosion deposited on the surface [8]. The corresponding changes in the weights were noted. At least three samples were tested, and average value was taken. Corrosion rates were computed using the equation, Corrosion rates $=534 \mathrm{~W} / \mathrm{DAT}$ mpy Where, $\mathrm{W}$ is the loss in grams, $\mathrm{D}$ is the density of the specimen in gram/cc, A is area of the specimen $\left(\mathrm{inch}^{2}\right)$ and $\mathrm{T}$ is the exposure time in hours.

\section{Electrochemical measurements}

Tafel polarization studies: Electrochemical measurements were carried out by most metallic corrosion occurs using an electrochemical work station, $\mathrm{CH}$ instruments (USA) [9]. Tafel plot analysis is 
Citation: Pruthviraj RD, Vishwa V (2017) Electrochemical Characterization of Al 1100 Alloy in Different Concentration of Ammonium Chloride Solution at Laboratory Temperature. Chem Sci J 8: 175. doi:10.4172/2150-3494.1000175

Page 2 of 4

performed by extrapolating the linear portion of the measurements were carried out using conventional three electrode Pyrex glass cells with platinum counter electrode and $\mathrm{Ag} / \mathrm{AgCl}$ electrode as reference electrode [10]. All the values of potential are therefore referred to the SRE. Finely polished by the Al 1100 specimens of $1 \mathrm{~cm}^{2}$ surface area was exposed to corrosion medium of different concentration of Ammonium chloride solution $(0.1 \mathrm{~m}, 0.75 \mathrm{~m}, 0.50 \mathrm{~m}, 0.025 \mathrm{~m})$ at laboratory temperature and allowed to establish a steady state open circuit potential [11]. The potentiodynamic current potential curves are recorded by polarizing the specimen to $250 \mathrm{mv}$ catholically and $+250 \mathrm{mv}$ anodically with respect to Open Circuit Potential (OCP) at scan rate of $5 \mathrm{mv}$.

Electrochemical Impedance Spectroscopy studies (EIS): Electrochemical Impedance Spectroscopy (EIS), method is very use full in characterizing electrodes behavior. The electrode characterization includes the determination of the polarization [12]. The corrosion behavior of the $\mathrm{Al} 1100$ was also obtained from EIS studies using electrochemical work station instruments (USA). In EIS technique a small amplitude ac signal of $10 \mathrm{mv}$ and frequency spectrum from $100 \mathrm{kHz}$ to $0.01 \mathrm{~Hz}$ was impressed at the OCP and impedance data was analyzed using Nyquist plots. The charge transfer resistance was extracted from the diameter of the semicircle in Nyquist plots [13]. In all the above measurements, at least three similar results were considered, and their average values are reported. The scanning electron microscope images were recorded to establish the interaction of acid medium with the metal surface using JEOL JSM-6380LA analytical scanning electron microscope (CPRI).

\section{Results and Discussion}
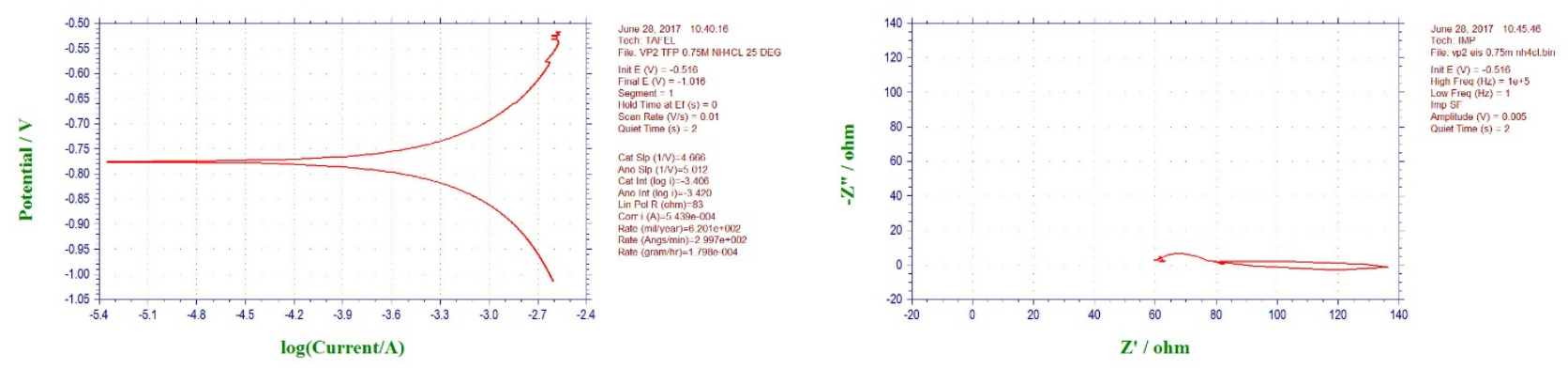

Figure 1: Potentio dynamic studies of $\mathrm{Al} 1100$ in $1 \mathrm{M} \mathrm{NH}_{4} \mathrm{Cl}$ solution.
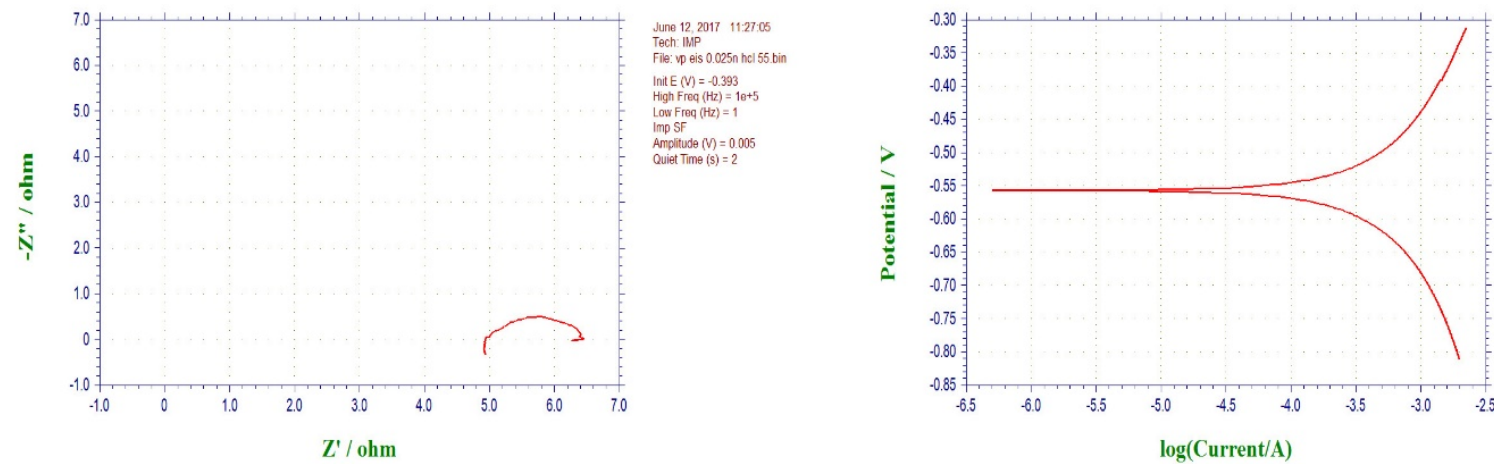

June 28.2017
Terh TAFEL $11: 42.40$ TeCh: TAFEL
File: VPS TFP 0.54 NHACL 25 DEGR $\ln E(E)=-0.312$
Final $E(N)=-0.812$ Segmert $=1$
Hold Time at $\mathrm{Ef}(\mathrm{s})=0$

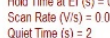

Figure 2: Potentio dynamic studies of $\mathrm{Al} 1100$ in $0.75 \mathrm{M} \mathrm{NH}_{4} \mathrm{Cl}$ solution. 
Citation: Pruthviraj RD, Vishwa V (2017) Electrochemical Characterization of Al 1100 Alloy in Different Concentration of Ammonium Chloride

Page 3 of 4
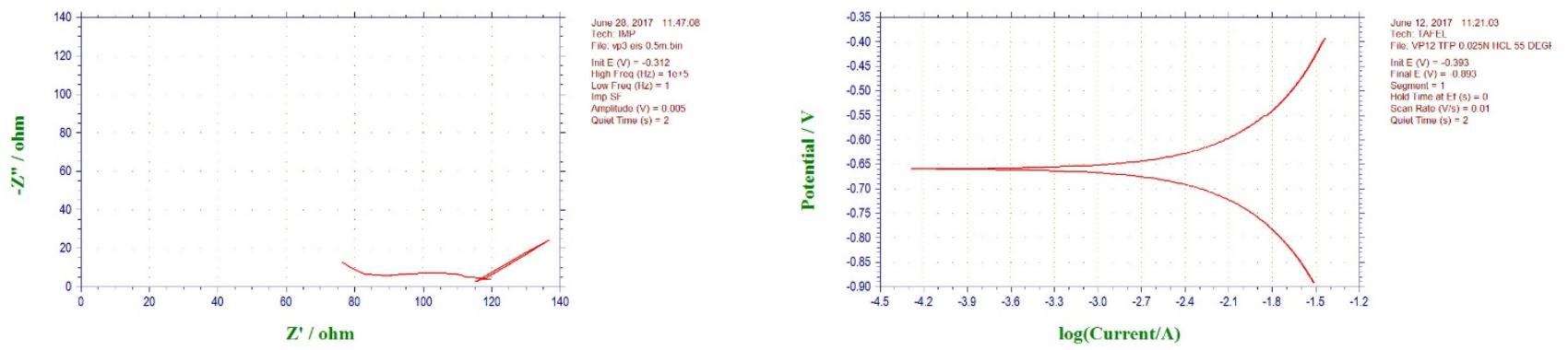

Figure 3: EIS studies of $\mathrm{Al} 1100$ in $0.5 \mathrm{M} \mathrm{NH}_{4} \mathrm{Cl}$ solution.
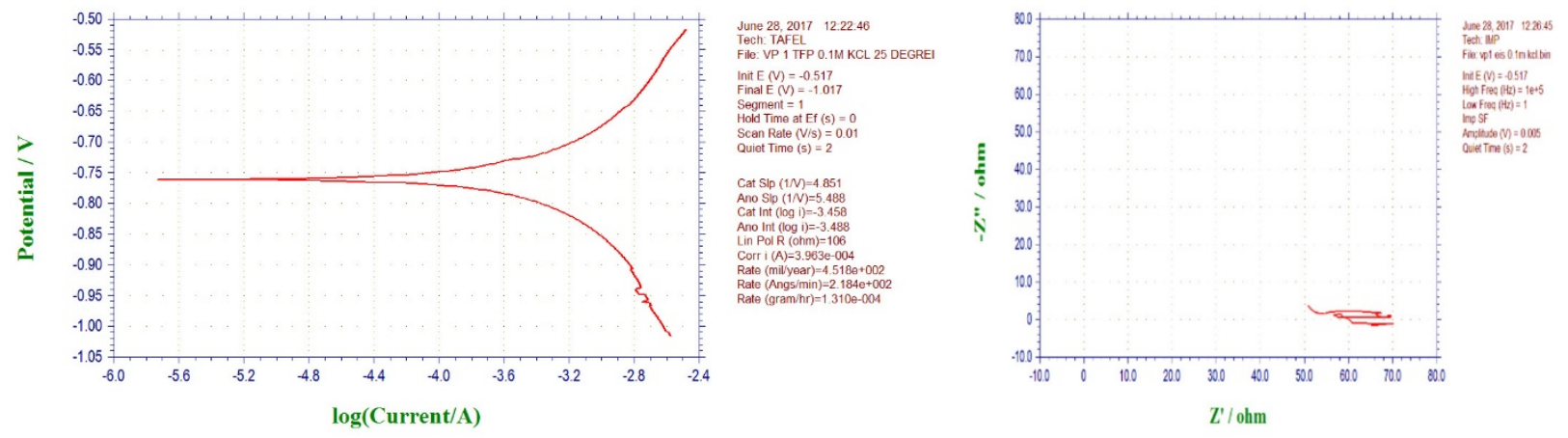

Figure 4: Potentio dynamic studies of $\mathrm{Al} 1100$ in $0.25 \mathrm{M} \mathrm{NH}_{4} \mathrm{Cl}$ solution.

\section{Effect of test duration}

The corrosion rate mpy measurement as a function of exposure time in the static time immersion test is shown in the Figure 1. The trend observed in all the cases show decrease in corrosion with increase in test duration. It is clear from graph that the resistance of the composite to corrosion increase as the exposure time increases this eliminates the possibility of hydrogen bubbles clinging on to the surface of the specimen and forming a permanent layer affecting the corrosion process. This layer protects further corrosion in a basic media. But exact chemical nature of such protective film still is not determined.

\section{Corrosion morphology}

Pit morphology on sensitized of the specimen of Al 1100 the weight studied of opt potentiodynamic corrosion experiment test has been used to induce the pitting corrosion of the specimen (Figure 2). Pits usually grow more rapidly in-depth specimen spread pitting are also observed on the surface of the specimen showed pits, cracks and flakes are formed on the surface of the specimen, $2 \mathrm{Al}+6 \mathrm{HCl} \rightarrow 2 \mathrm{AlCl}_{3}+3 \mathrm{H}$, $2 \mathrm{Al}+6 \mathrm{H}_{2} \mathrm{O} \rightarrow 2 \mathrm{Al}(\mathrm{OH})$. The above reaction raises directly influenced by the variables. the temperature of the acidic solution specimen exposure $25^{\circ} \mathrm{C}$ is shown in Figures 3 and 4 (I-corr) were determined by end I-corr increase inhibitor $\mathrm{nH} 23+3 \mathrm{H}_{2}$ area hydrogen concentration in solution exposure time of the specimen and the specimen area is exposed the researcher have reported on static corrosion the rate of corrosion decreases with increase in exposure of the time to move noble potentials.

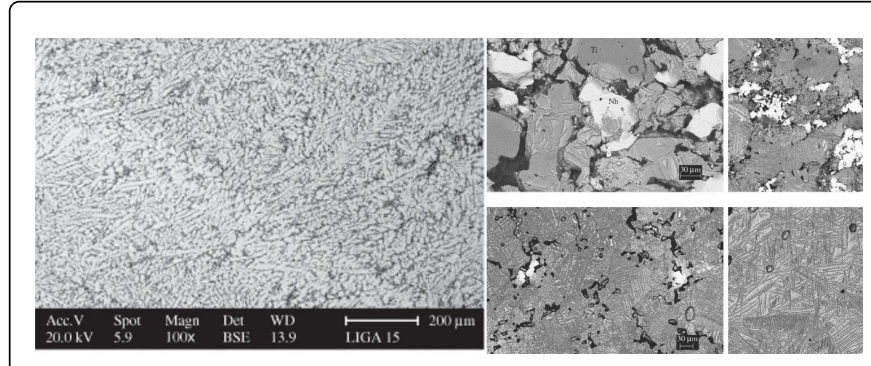

Figure 5: SEM photographs of AL 1100 before and after corrosion test in $\mathrm{NH}_{4} \mathrm{Cl}$.

\section{$\mathrm{X}$-ray Diffraction (XRD) analysis}

XRD of the oxidation products formed on the carbon steel surface polarized potentiodynamically in formation water containing $0.3 \mathrm{M} \mathrm{Cl}$ and $0.1 \mathrm{M} \mathrm{Na}_{2} \mathrm{SO}_{4}$ solution at a scan rate of $10 \mathrm{mV} \mathrm{s}^{-1}$ was performed at speci ic polarization potential $(\mathrm{EPA}<\mathrm{E}<\mathrm{Epic}$ ) (Figure 5). The data obtained con irmed the existence of $\mathrm{Fe}_{4}(\mathrm{OH})_{8} \mathrm{Cl}(\mathrm{s}$ ) (Chloride green rust) and $\mathrm{Fe}_{6}(\mathrm{OH})_{12} \mathrm{SO}_{4}(\mathrm{~s})$ (Sulfate green rust) on the surface of metal. It is obvious from data also that the effect of adding of increasing amounts $(0.05-0.2 \mathrm{M})$ of $\mathrm{NaHCO}_{3}$ (the $\mathrm{pH}$ was 8.9 for all solutions and no $\mathrm{pH}$ adjustment was done) to the formation water contain chloride ion decreases the anodic dissolution of carbon steel and shi ts its potential EPA to more noble direction. Further inspection of Figure 6 reveals that the pitting potential Epic moves to a more positive direction with 
Citation: Pruthviraj RD, Vishwa V (2017) Electrochemical Characterization of Al 1100 Alloy in Different Concentration of Ammonium Chloride Solution at Laboratory Temperature. Chem Sci J 8: 175. doi:10.4172/2150-3494.1000175

Page 4 of 4

increasing bicarbonate ion concentration, indicating the protective effect of $\mathrm{NaHCO}_{3}$ towards the pitting corrosion processes of carbon steel. This maybe resulted from reduced solubility of the corrosion product in presence of bicarbonate ion, which stimulated and protecting corrosion film. The results are explained in terms of the more favorable formation of an iron hydroxy-carbonate complex (called green rust carbonate) than the formation of the corresponding green rust chloride complex (Table 2). The data obtained from XRD analysis confirmed the existence of $\mathrm{Fe}_{2}(\mathrm{OH})_{2} \mathrm{CO}_{3}$ on the surface of metal.
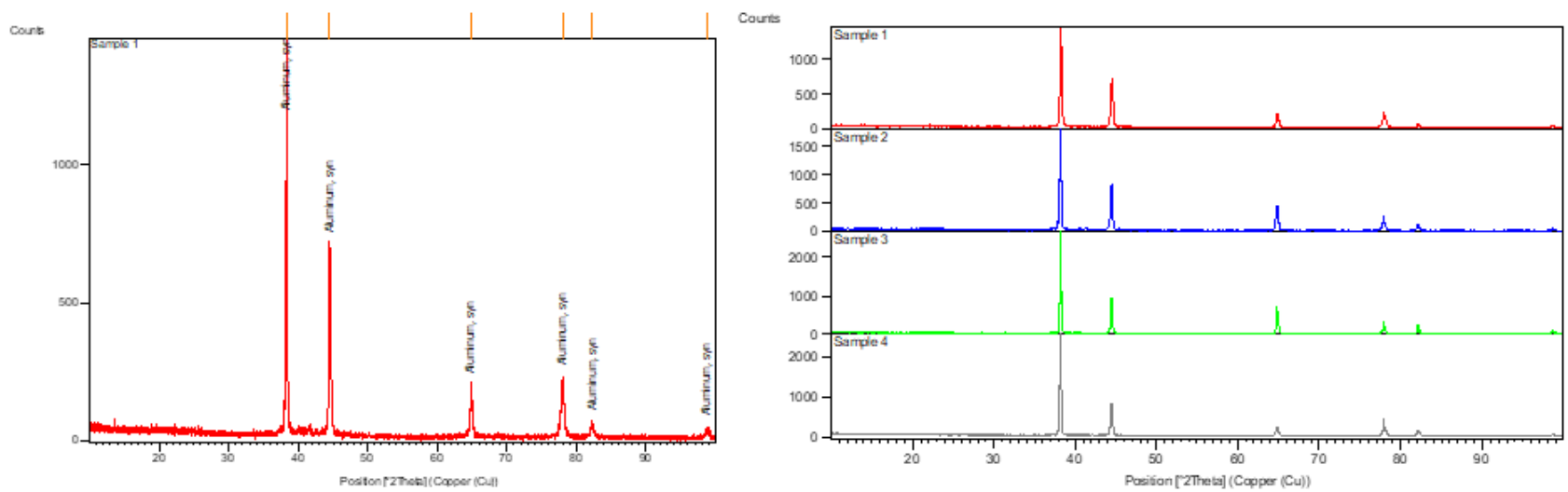

Figure 6: XRD Al 1100.

\begin{tabular}{|c|c|c|c|c|}
\hline Pos. $\left({ }^{\circ} \mathbf{2}\right.$ Th.) & Height (cts) & FWHM ('2Th.) & D-spacing (A) & Rel. Int. (\%) \\
\hline 38.3321 & 1416.41 & 0.2204 & 2.34822 & 100 \\
\hline 44.5368 & 675.81 & 0.2834 & 2.03443 & 47.71 \\
\hline 64.9194 & 174.88 & 0.3149 & 1.43642 & 12.35 \\
\hline 78.0022 & 204.22 & 0.4408 & 1.225 & 14.42 \\
\hline 82.2327 & 44.16 & 0.3779 & 1.17237 & 3.12 \\
\hline 98.7606 & 27.25 & 0.768 & 1.01482 & 1.92 \\
\hline
\end{tabular}

Table 2: Pitting potential epic moves to a more positive direction with increasing bicarbonate ion concentration.

\section{Acknowledgement}

The authors gratefully acknowledge VGST, Govt. of Karnataka for financial support under the project CISEE/2014-15/GRD No. 325. Also express their gratitude to Management and Principal, Raja Rajeswari College of Engineering, Bangalore for providing infrastructural facilities.

\section{Conclusion}

The Aluminium content in 1100 alloy plays a significant role in the corrosion resistance of the material. Increase in the percentage of Sic will be advantage to reduce the density and increase in the strength of the alloy, but the corrosion resistance is there by significantly reduced $\mathrm{Al}$ 1100. XRD pattern shows the composition of Al I-corr increases 1100 alloy with increase in $\mathrm{NH}_{4} \mathrm{Cl}$ corrosion rate decrease with decrease in $\mathrm{NH}_{4} \mathrm{Cl}$ SEM photo graphs shows with increase in concentration of $\mathrm{NH}_{4} \mathrm{Cl}$ solution.

\section{References}

1. Harris SJ (1988) Cast metal matrix composites. Mater Sci Technol 4: 231-239.

2. Hwan YHK, Lee S, Kim NJ (2011) Fracture mechanisms of a 2124 aluminium matrix composite reinforced with Sic whisker. Metall Mater Trans 23: 2589-2596.

3. Henriksen BR, Johnsen TE (1990) Influence of microstructure of fibre/ matrix interface on mechanical properties of $\mathrm{Al} / \mathrm{Sic}$ composites. Mater Sci Technol 6: 857-863.

4. Karnezis PA, Durrant G, Cantor B (1998) Characterization of reinforcement distribution in cast $\mathrm{AL}$-alloy/SiCp composites. Mater Charac 4: 97-109.

5. Bae BK, Hoon L (2002) Strength of Al-ZN-Mg-Cu matrix composites reinforced with Sic particles. Metal Meter Trans 33: 455-465.

6. Xia X, McQueen HJ, Zhu H (2002) Fracture behavior of particles reinforced metal matrix composites. Appl Compos Matter, pp. 17-31.

7. Barnhurst RJ, Farge KC (1986) In proceedings of international symposium on Zinc Aluminium, ZA casting Alloys. Lewis GP, Barnhurst RJ, Loong CA (eds.) Toronto Cim, pp. 85.

8. Lo SHJ, Dionne S, Sahoo M, Hawthorne HM (1992) Mechanical and tribological properties of zinc-aluminium metal-matrix composites. Matter Sci 27: 5681-5691.

9. Smith W (1993) Structures and properties of engineering's alloys. 2nd Edition, McGraw-Hill, New York, USA pp. 567.

10. Srivatsan TS, Ibrahim IA, Mohamed FA, Lverinia EJ (1991) Processing techniques for particulates- reinforced metal aluminium matrix composites. J Mater Sci 26: 5965-5978.

11. Seah KHW (1998) Effect of artificial ageing on tensile strength of ZA-27 short glass fibre reinforced composite. Journal of the Institution of Engineers, Singapore 38: 4 .

12. Desalazar JMG, Urefia A, Mazanedo S, Barrens M (2011) Corrosion behavior of AA6061 and AA7075.

13. Acevedo PA and Sundaram PA (2017) Reinforced with $\mathrm{Al} 2 \mathrm{O} 3$ particulates in aerated 3.5 percent chloride solution Potentio dynamic measurements and microstructures evaluation. 26: 69-75. 